\title{
The in Silico Study of Nutmeg Seeds (Myristica fragrans Houtt) as Peroxisome Proliferator Activated Receptor Gamma Activator Using 3D-QSAR Pharmacophore Modelling
}

\author{
M. Muchtaridi ${ }^{1 *}$, Karen Low ${ }^{1}$, Keri Lestari ${ }^{2}$ \\ ${ }^{1}$ Department of Pharmaceutical Analysis and Medicinal Chemistry, Faculty of Pharmacy Universitas Padjadjaran, Bandung, Indonesia.Jl. Bandung- \\ Sumedang KM-21, Jatinangor, 45363., ${ }^{2}$ Department of Pharmacology and Clinical Pharmacy, Faculty of Pharmacy Universitas Padjadjaran, Bandung, \\ Indonesia.
}

\begin{tabular}{|c|c|}
\hline ARTICLE INFO & ABSTRACT \\
\hline Article history: & \multirow{9}{*}{$\begin{array}{l}\text { In this study, we created a pharmacophore models from a dataset of agonists for PPAR gamma receptor using } \\
\text { the Catalyst/Hypogen module. A training set consists of } 22 \text { compounds activity range between } 0.1 \text { to } 3,500 \mathrm{nM} \text {, } \\
\text { were carefully selected. In previous study, molecular docking of macelignan against PPAR } \gamma \text { binding pocket } \\
\text { showed a free energy binding of }-11.07 \mathrm{~kJ} / \mathrm{mol} \text {, interaction with the hydrophobic pocket (diphenyl pocket)(Celik } \\
\text { et al., 2007), and a hydrogen bond network (His } 323 \text {, Tyr } 473 \text {, His } 449 \text { and Ser289). The pharmacophore model } \\
\text { (Hypo1), consisting of } 5 \text { features, i.e. one hydrogen bond acceptor (HBA), negative ionizable (NI), ring } \\
\text { aromatic (RA) and two hydrophobics (HY) features, and one excluded volume. Hypo1 has the lowest total cost } \\
\text { value ( } 92.055) \text {, the highest cost difference ( } 40.9316) \text {, the lowest RMSD ( } 0.591049) \text {, and the best correlation } \\
\text { coefficient (0.972949). Fourteen natural substances reported from nutmeg seeds (Myristica fragrans HOUTT.) } \\
\text { were then mapped against Hypo1, and macelignan shows a fair fit value of } 7.00102 \text { with an estimated value of } \\
1271.990 \mathrm{nM} \text {. This concludes, macelignant in nutmeg might have antidiabetic properties via PPAR } \gamma \text { receptor } \\
\text { activation. }\end{array}$} \\
\hline Received on: 19/01/2016 & \\
\hline Revised on: 14/04/2016 & \\
\hline Accepted on: & \\
\hline Available online: $26 / 09 / 2016$ & \\
\hline Key words: & \\
\hline Anti-diabetic, Hypogen, & \\
\hline pharmacophore modelling, & \\
\hline PPAR $\gamma$ & \\
\hline
\end{tabular}

\section{INTRODUCTION}

Peroxisome Proliferator-Activated Receptors (PPARs) are members of the nuclear receptor super-family that is involved in protein gene expression for energy, glucose and lipid metabolism, proliferation and differentiation of adipocyte, as well as insulin sensitivity (Arck et al., 2010; Hiukka et al., 2010; Farce et al., 2009). Three isoforms of these core receptors have been identified so far: PPAR $\alpha$, PPAR $\beta / \delta$ dan PPAR $\gamma$. Each of them has different selectivity towards type of tissue, type of ligand, and finally, unique biological response. PPAR $\gamma$ is mostly expressed in adipose tissue, colon and macrophages, and has been proven for its role in regulating carbohydrate metabolism as well as fatty acid storage. Finding a new and poten ligand for PPAR $\gamma$ is the main focus in research for treating patients with

* Corresponding Author

Emails: muchtaridi@unpad.ac.id
Type II diabetes mellitus, as it can restore insulin sensitivity. PPAR $\gamma$ agonist has made a big attraction in the clinical management of cardiovascular risk factors associated with metabolic syndrome and Type 2 diabetes mellitus (Pearson, 2009). A few classes of PPAR $\gamma$ agonist have been reported to possess anti-diabetic properties, such as: thiazolidindiones, dihydrobenzofurans, dihydro-benzopyrans, benzofuran benzoxazoles and $\alpha$-amino- $\beta$-phenylpropanoic acid derivatives (Henke, 2004b). Thiazolidinediones (TZDs) is an important class of PPAR $\gamma$ synthetic agonist (Feldman et al., 2008).

TZDs are anti-diabetic agents that work on adipose tissue and increase insulin sensitivity. At this point, it is still used in the effort to treat Type II diabetes mellitus (Pourcet et al., 2006). Despite the clinical benefit of TZDs, they are related with side effects such as an increased body weight, an increased adipogenesis, kidneys fluid retention, and possible increase in cardiovascular disorder occurrences (Jones, 2010). 
Thus, new PPAR $\gamma$ activator with an increased therapeutic efficacy and lesser side effects is necessary. Partial PPAR agonist is recently popular as a promising and new generation of PPAR activator. Partial agonist induces alternative receptor confirmation and as such, recruits different co-activator, which results in a different transcription effect when compared with TZDs. Therefore, it is indicated that such partial agonists will probably offer the required effectiveness and reduce side effects (Chang $e t$ al., 2007; Yumuk, 2006). Natural products are an important and promising source in the discovery of new potent drugs (Newman and Cragg, 2007). Here, we created a pharmacophore models from a dataset of agonists for PPAR $\gamma$ receptor using the Catalyst/Hypogen module for predicting the nutmeg seeds compounds. In the previous study, Najjar et al. (2011) generated the pharmacophoric space of PPARg using seven diverse sets of activators (Al-Najjar et al., 2011). However, the compounds screened was not natural compounds. Thus, the purpose of this study was to identify the functional groups or features that activate the human PPAR $\gamma$ as agonist. The approach with identification and modelling of pharmacophore at 2-aryloxy-3-phenyl-propanoic acid has been done with in silico method.

\section{MATERIAL AND METHOD}

\section{Selecting Training Set Compound}

Choosing the training set is important for generating a hypothesis in the Hypogen and has to follow certain ground rules, such as a minimum of 16 varieties of structural compound has to be chosen to avoid by chance of correlation. Activity data was limited at least 4 magnitude order. The selected compounds should have simple and clear information. Any redundancy (extreme) in the structural features or in the activity data must be avoided. Inactive compound due to steric factor is unsuitable to be used in the training set because Catalyst is limited to accommodate that such cases.

\section{Data Set mining}

The number of 117 ligands were collected from some literatures as dataset that substraction as training set and external set.that has activity against PPAR $\gamma$ (Martres et al., 2008; Henke, 2004a; Koyama et al., 2004; Shibata et al., 2012; Oon Han et al., 2007). The database were chosen based on similar bioassay method as shown in Fig. 5. Activity values were presented as Effective Concentration, or $\mathrm{EC}_{50}$.

Dataset was then divided into training set and test set. The Most Active (MA) compound gives an important information for pharmacophore modeling and a few Moderately Active (M) compound as well as Less Active (L) compound are also important in spreading the range for activity value as large as possible. A number of 20 ligands that fulfilled the criteria were used as training set and the remaining 25 compounds were selected as a test set based on the formula of 1.1. and 1.2. Training set was selected using formula (1), while the external set was chosen beside of training set. For the training set data, attribute of uncertainty was set up to show uncertain value with a score of 3 on the spreadsheet. This means, the activity of the actual ligand in the training set would be in the range of $1 / 3$ to 3 times from the ligand's activity.

Activity range of PPAR $\gamma$ compound is classified as followed: Most Active $(<0,9 \mathrm{nM})$, Moderate $(0,9 \mathrm{nM}-316 \mathrm{nM})$ and Less Active $(>316 \mathrm{nM})$. Compound's activity is determined by calculation with the formula:

$$
\begin{aligned}
& \text { MA * UncMA - A/ UncA >0.0 } \\
& \log (\mathrm{A})-\log (\mathrm{MA})>3.5
\end{aligned}
$$

Description: $\mathrm{MA}=$ compound with highest activity (lowest $\mathrm{EC}_{50}$; UncMA=uncertainty of activity is measured and $\mathrm{A}=$ activity from active compound (Abu Hammad and Taha, 2009).

\section{Pharmachopore Modeling \\ Generation of Conformation Library of Bioactive Compounds}

For the training and test sets molecules, conformational models representing their available conformational space were calculated. All molecules were built using the 2D and 3D sketcher of Hyperchem 7.0, and optimized using MM2 in Hyperchem 7.0. A conformational set was generated for each molecule using the poling algorithm and the best energy option, based on CHARMm force field from Discovery Studio 2.5 (Brooks et al., 1983; Musfiroh et al., 2013). The molecules associated with their conformational models were mapped onto the pharmacophore model using the "best fit" option to obtain the bioactive conformation of each molecule.

\section{Pharmacophore Models}

A number of 255 Conformers was chosen to be minimized as best conformation, and $20 \mathrm{kcal} / \mathrm{mol}$ was set as energy threshold as global energy minimum for conformational searching (Wang et al., 2008), this protocol is available in DS 2.5 packages. The best pharmacophore models was validated according to Deng et al. (Deng et al., 2008) in terms of cost functions and other statistical parameters which were calculated by HypoRefine module during hypothesis generation. A good pharmacophore model should have a high correlation coefficient, lowest total cost and RMSD values, and the total cost should be close to the fixed cost and away from the null cost. The best pharmacophore model was further validated by external test set and Fischer's randomization test (Abu Hammad and Taha, 2009).

\section{Molecular Docking}

This study used LBD (ligand binding domain) of peroxisome proliferator-activated receptor gamma or PPAR $\gamma(\mathrm{PDB}$ id : 3HOD) (Fracchiolla et al., 2009) structure with $2.1 \AA$ resolution. The crystal structure were selected according to best resolution or lower resolution value, and also have R-free and Rvalue lower than 0.25 (Muchtaridi et al., 2014). The 3D structures of lignan derivatives compounds were constructed using Hyperchem 7, then were optimized using Austin Model 1 (AM1). Docking results have been saved in a dlg file to be analyzed to get 
information about ligand orientation, binding energy value and $\mathrm{K}_{\mathrm{i}}$ value (Ikram et al., 2015). Molecular docking method was validated by re-docking of the ligand of crystal as control doocking against PPAR $\gamma$ (PDB id: 3HOD). Autodock 4.0 was employed to know the interaction between ligand and receptor (Muchtaridi et al., 2014).

\section{RESULTS}

\section{D-QSAR Pharmacophore Model}

The Hypogen that embedded in DS 2.5. was generated 100 models. The results of the pharmacophore hypothesis from the 3D QSAR Pharmacophore were presented in Table 1. The results showed that hypothesis 1 , run 9 (Hypo1) was the best hypothesis results in this study. This is based on the value of cost difference, which is the highest value of 40.9316, lowest root mean square error with value of 0.591049 , and highest correlation coefficient with value of 0.972949 .

Table 1: Hypothesis result of 3D QSAR pharmacophore for training set.

\begin{tabular}{ccccc}
\hline Run no. & Total cost & $\begin{array}{c}\text { Cost } \\
\text { diff. }^{\mathbf{1}}\end{array}$ & RMSD (̊̊) & Correlation (r) \\
\hline 4 & 89.4434 & 40.7476 & 0.628438 & 0.96755 \\
5 & 89.6173 & 40.5737 & 0.683979 & 0.962129 \\
6 & 93.0029 & 37.1881 & 0.788700 & 0.949402 \\
7 & 91.2994 & 38.8916 & 0.799089 & 0.947947 \\
$\mathbf{9}$ & $\mathbf{8 9 . 2 5 9 4}$ & $\mathbf{4 0 . 9 3 1 6}$ & $\mathbf{0 . 5 9 1 0 4 9}$ & $\mathbf{0 . 9 7 2 9 4 9}$ \\
\hline
\end{tabular}

${ }^{1}($ Null cost-total cost $)$, null cost $=130.191$. All cost values are in bits.

This proved that there was more than $97 \%$ correlation between estimated activity and actual activity from the training set compounds. Fixed cost, total cost, and null cost are 84.8473, 89.2594 and 130.191, respectively. Ideal difference between null cost and fixed cost are the value in between 70-100 bit. The difference between null cost and fixed cost that lies between 40-60 bits indicates that correlation probability from Hypo1 is $75 \%-90 \%$ (Accelrys, 2002). The bigger difference and the higher probability could identify a good pharmacophore model. Configuration cost value has to be less than 17 and configuration value obtained is 16.4502.(Sutter et al., 2000). The 3D space and distance constraints of these pharmacophore features are shown in Fig. 2B. Pharmacophore features of Hypol was presented in Figure 1 (A), consisting of 5 pharmacophore features, employing HBA, NI, RA, two HY and one excluded volume in Figure 1(B), shows the distance between features in Amstrong $(\AA)$ units. The distance between features of HY1 and HY2 was 6.6885 $\AA$. HY1 to HBA was $4.220 \AA$, HBA to NI was $12.096 \AA$, HBA to RA, 7,401 $\AA$ and RA to NI was 5,880 $\AA$. This distance happens to be a combination of electrical and steric features of compounds that is necessary to ensure an optimal interaction of molecules with PPAR $\gamma$ to trigger its biological response (agonist) (Manetti et al., 2003). Figure 1c showed a lot of hydrophobic interactions in the binding pocket PPAR $\gamma$ (hydrophobic character). HBA interacted with the amino acid residue HIS449 (2.4 $\AA$ ), HIS323 (3.0 $)$ ) and

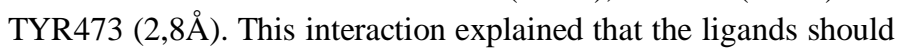
have hydrophobic interactions and hydrogen bonding, to ensure their biological activity (PPAR $\gamma$ agonist). Mapping results of the training set compound on Hypol with the activity (experimental and estimated) and their corresponding error.

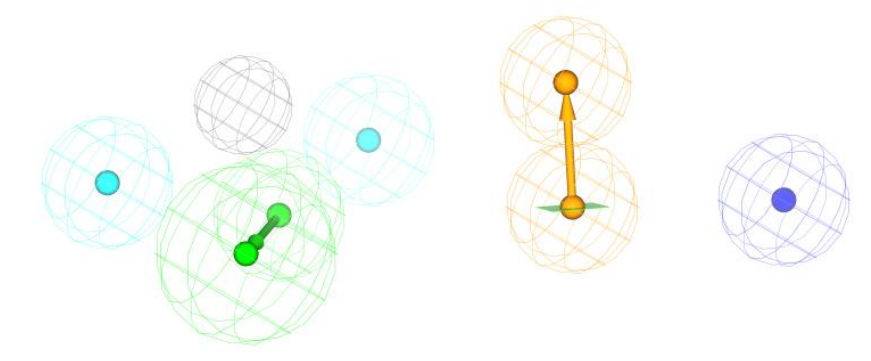

A

B

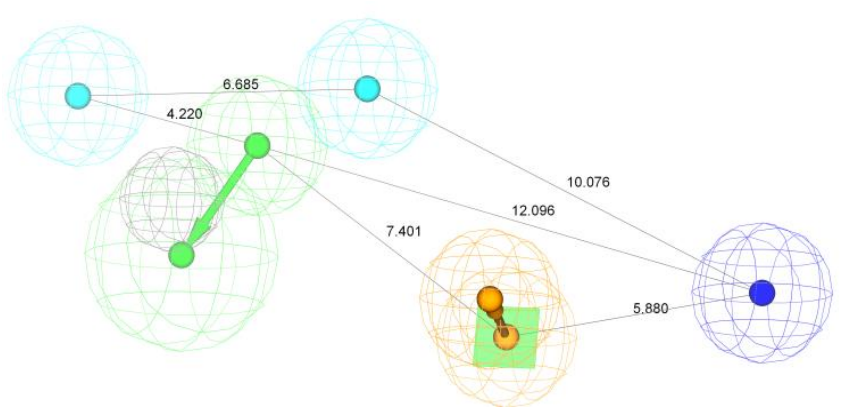

C

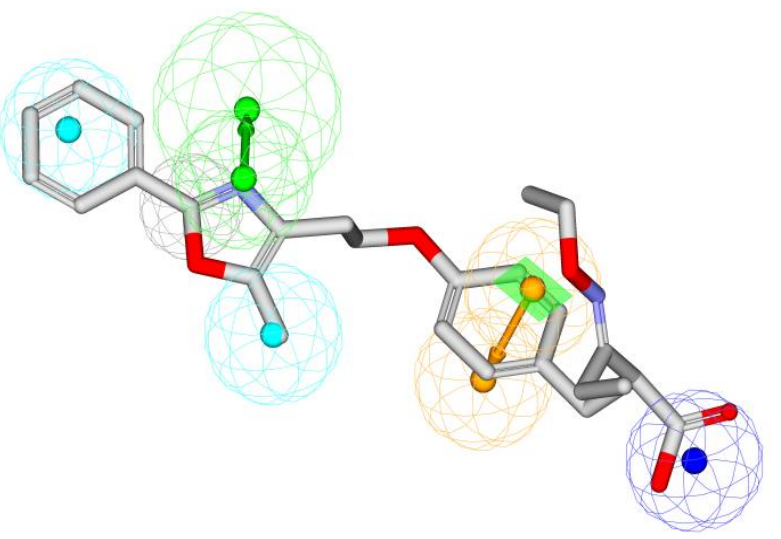

$\mathrm{D}$

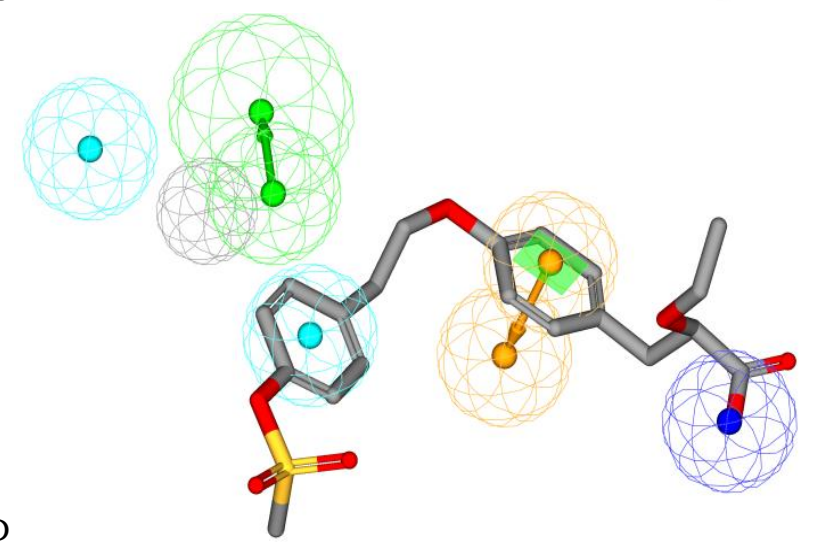

Fig. 1: Feature of Best Pharmacophore with Validation by Hyporefine Run in DS 2.5. (a) The best HypoRefine pharmacophore model, Hypol. (b) 3D spatial relationship and geometric parameters of Hypo1. (c) Mapping of Hypo1 to MA 6 from training set (d) Mapping of Hypo1 to LA 105 from training set. Pharmacophore features are color coded; green: hydrogen-bond acceptor (HBA), cyan - hydrophobic feature (Hy), dark blue - negative ionizable $(\mathrm{N})$, orange - aromatic ring (AR), and grey - excluded volume. 
All most active (MA) compounds have been correctly predicted by Hypo1. All MA compounds mapped all pharmacophore features covering HBA, NI, AR and HY. One of MA compounds, i.e. compound 6 with EC50 value of $0.10 \mathrm{nM}$ shows a fit value of 10.85 (Experiment: 0.1nM; Prediction: 0.18nM). Fit value indicates how well the pharmacophore features overlay chemical features in the molecule (Guner, 2005). A higher fit value is better [32]. Figure (3A), showed the compound 6 with HBA feature fitted with nitrogen $\mathrm{sp} / \mathrm{sp} 2$ hybridization that has free electrons and smaller or no charge. The NI feature fitted against the carboxylate functional group, AR mapped to the benzene and both HY with methyl and phenyl respectively.

\section{Validation of Pharmacophore Model Fischer Randomization test}

Fischer Randomization is embedded in the DS 2.5 package to evaluate the best pharmacophore model. CatScramble module within Catalyst was performed to evaluate the models.

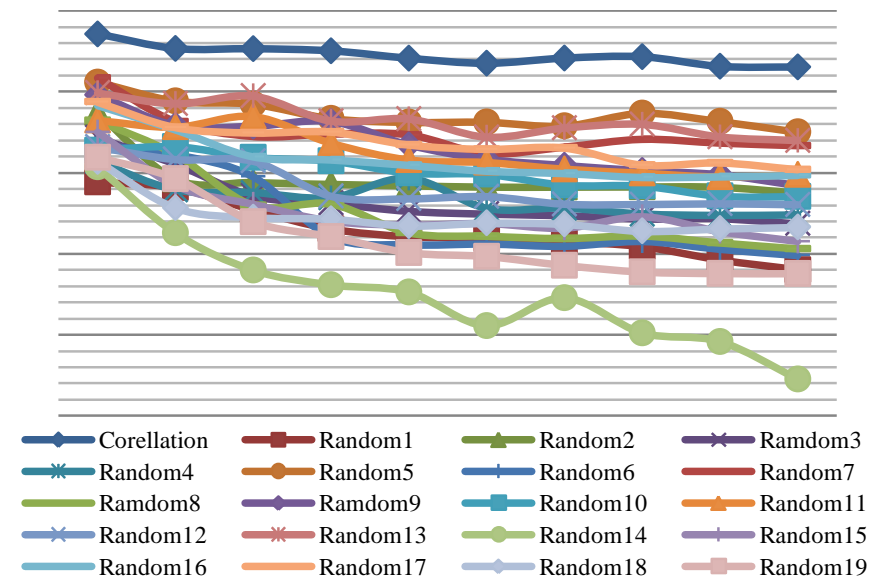

(a) Correlation (r2) of Hypo1

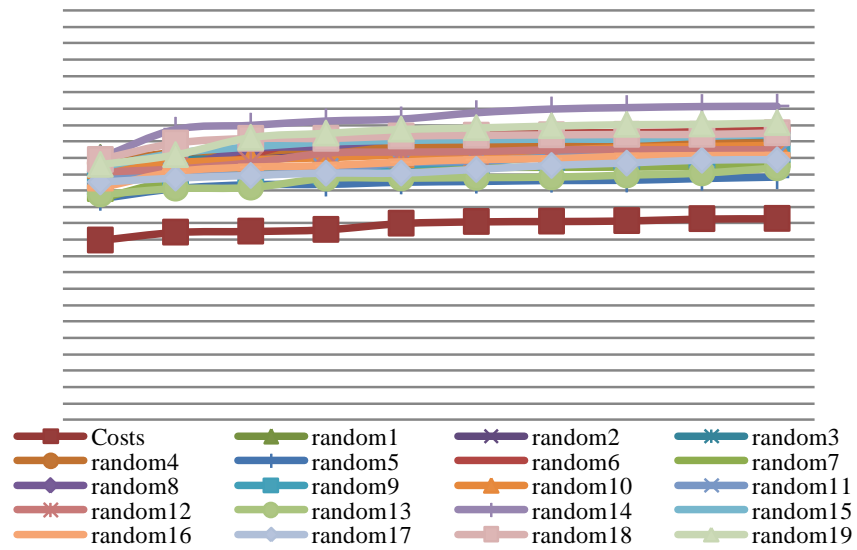

(b) Total cost of Hypo1

Fig. 2: The difference in total cost (b) and correlation (a) of hypotheses between the initial spreadsheet and 19 random spreadsheets after CatScramble run.

This statistical program in CatScramble mixes up activity values of all training set compounds to check whether there are strong correlation between the structure and activity.
Cross validation test explained that Hypol has a significant value of $95 \%$ and the results. It could be seen in Figure $2 \mathrm{a}$ that the correlation value (r) on all pharmacophore models (Random 1 Random 19) were smaller than the Hypol correlation, which showed highest correlation between experimental activity and predictive value. Fischer randomization test was done to assess the predictive quality of Hypo1. COST value indicatedthat the difference between estimation values andexperiment value. COST data obtained from running of 3D QSAR from every hypothesis was created a mold to test for Fischer randomization. Compounds were taken at random from every hypothesis, and then compared with the other hypothesis. Based on the results of Fischer randomization (Figure 2b), it was shown that data cost from training set compound was taken randomly by Hypo1 that showed the lowest COST. Both COST value and correlation showed that Hypo1 was the best hypothesis.

\section{Test set methods}

Subsequently, all the test set molecules were prepared by the same way as that for the training set molecules. Hypol was applied to map the 25 test set compounds which gave a correlation coefficient of between experimental and estimated activities as shown in estimated Fig 4.

The results showed that all ligands with MA activity were predicted accurately, except for ligand 6 and 10, where by the ligand is underestimated became $\mathrm{M}$.

From all the M ligands, only ligand 45 was overestimated to have MA activity. LA ligands were all predicted accurately as well, except for ligand 63, in which it is overestimated into MA. Hypo1 shows a correlation as large as 0.9011 , which means that there are good relationship between experimental value and estimated value. A linear regression showing the similarity of experimental activity and estimated activity is shown in Figure 3.

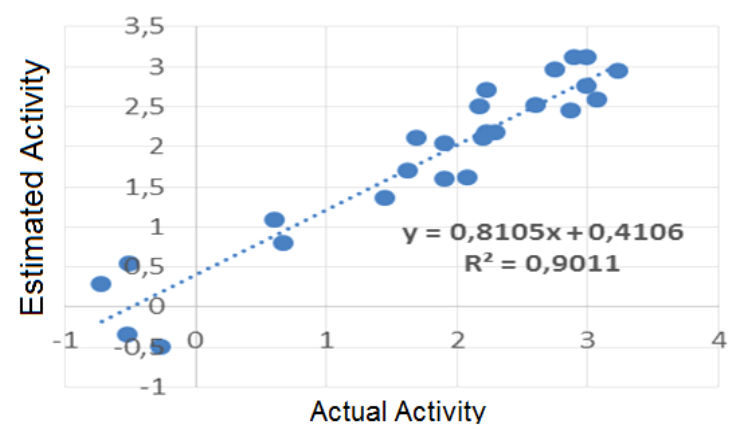

Fig. 3: Plot of the correlation (r) between the experimental activity and the predicted activity by Hypol for the test set molecules and the training set molecules.

Figure 4 showed that the character of the PPAR $\gamma$ binding pocket using software Ligand Explorer incoperated in the Protein Data Bank (PDB) website. Binding mdeof the lead compound was shown by the interaction between the amino acid residues with the binding site. Figure 1c shows a lot of hydrophobic interactions in the binding pocket PPAR $\gamma$ (hydrophobic character). Figure 1c and Figure 3 showed that HBA interacted with the amino acid residue 


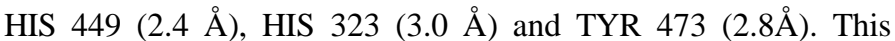
interaction suggested that the ligands should have hydrophobic interactions and hydrogen bonding, to ensure their biological activity (PPAR $\gamma$ agonist).

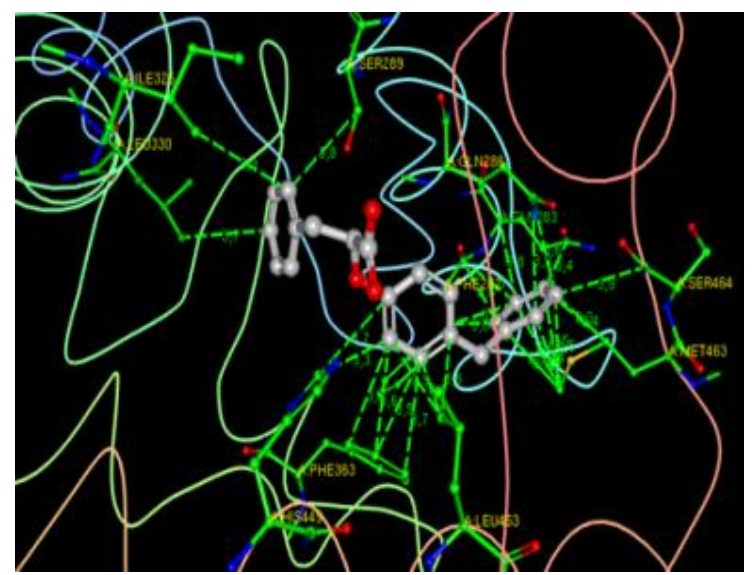

A

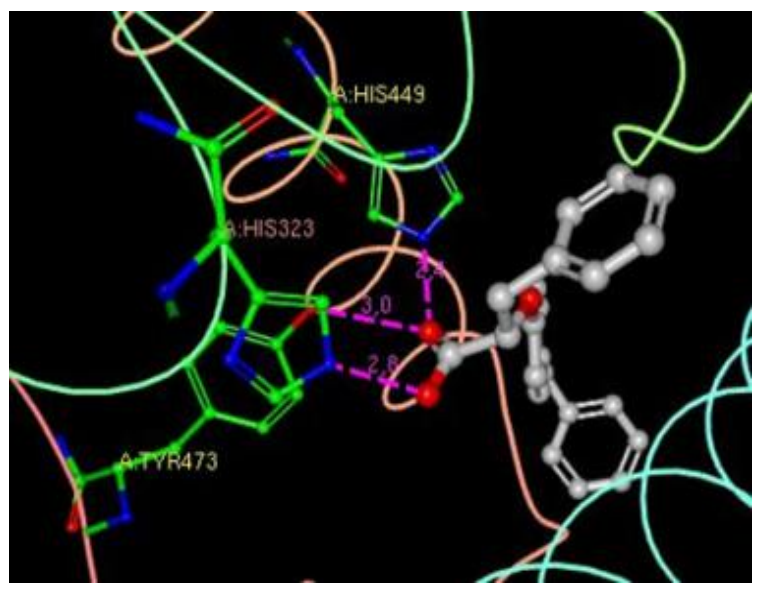

B

Fig. 4: Character of the PPAR $\gamma$ binding pocket using software Ligand Explorer incorporatedin the Protein Data Bank (PDB).(a) Hydropobic interaction in PPAR $\gamma$ binding pocket, (b) Hydrogen bond interaction in PPAR $\gamma$ binding pocket

\section{Activity Prediction of Nutmeg Seed Compounds}

Dihydro-di-isoeugenol (DHDE) in nutmeg (Myristica fragrans Hout) is recently developed as antidiabetic medicine with predicted mechanism of action as a dual agonist, i.e. PPAR $\alpha$ and $\gamma$ (Muchtaridi et al., 2014). In this study, 14 compounds derived from nutmeg plant, thiazolidinediones and lead compound 2-arloxy-3-phenyl propanoic acid (3HOD) which is expected active, was mapped by Hypo1 model.

Reason for mapping is to approach that even with different chemotypes, it can have good mapping results with Hypo1. From a total of 22 compounds, Malabaricone B from nutmeg extract shows highest fit value (8.10119) with estimated activity of $100.997 \mathrm{nM}$. However, this compound still doesn't have any research on its antidiabetic activity towards PPAR $\gamma$ receptor in vitro or in vivo. Antidiabetic currently being used in Indonesia now is Pioglitazone, with a fit value of 6.87839. Hypo1 predicted
EC50 $1686.99 \mathrm{nM}$ where experimental activity value of $1280 \mathrm{nM}$ (Casimiro-Garcia et al., 2013). Rivoglitazone shows fit value of 7.08281 (Kong et al., 2011; Schimke and Davis, 2007) with estimated activity value of $1053.62 \mathrm{nM}$

Although Malabaricone B shows highest fit value, it exists in a small quantity in nutmeg seeds which complicates the process being a marker and for extraction. Perhaps in future study, a new lead compound can be found or a better extraction technique for the nutmeg contents.

\section{CONLUCION}

Active pharmacophoric features for PPAR gamma agonist are Hydrogen Bond Acceptor (HBA) and Hydrophobic (HY). The compoundsof of nutmeg seeds (Myristica fragrans Hout) have the highest fit value (8.10119) with a total estimated of activity value $100,997 \mathrm{nM}$.

\section{Financial support and sponsorship: Nil.}

Conflicts of interest: There are no conflicts of interest.

\section{REFERENCES}

Abu Hammad, AM, and Taha, MO. Pharmacophore modeling, quantitative structure-activity relationship analysis, and shapecomplemented in silico screening allow access to novel influenza neuraminidase inhibitors. J Chem Inf Model, 2009; 49 (4): 978-996.

Accelrys. Understanding Hypogen Output. Accelrys 2002 [cited 25/6/2011 2011]. Available from http://www.esi.umontreal.ca/accelrys/ life/catalyst 47

Al-Najjar, BO, Wahab, HA, Tengku Muhammad, TS, ShuChien, AC, Ahmad Noruddin, NA, and Taha, MO. Discovery of new nanomolar peroxisome proliferator-activated receptor gamma activators via elaborate ligand-based modeling. Eur J Med Chem, 2011; 46 (6): 2513-2529.

Arck, P, Toth, B, Pestka, A, and Jeschke, U. Nuclear receptors of the peroxisome proliferator-activated receptor (PPAR) family in gestational diabetes: from animal models to clinical trials. Biol Reprod, 2010; 83 (2): 168-176.

Brooks, BR, Bruccoleri, RE, Olafson, BD, States, DJ, Swaminathan, S, and Karplus, M. CHARMM: A Program for Macromolecular Energy, Minimization, and Dynamics Calculations. J Comput Chem, 1983; 4 (2): 187-217.

Casimiro-Garcia, A, Heemstra, RJ, Bigge, CF, Chen, J, Ciske, FA, Davis, JA, Ellis, T, Esmaeil, N, Flynn, D, Han, S, Jalaie, M, Ohren, JF, and Powell, NA. Design, synthesis, and evaluation of imidazo[4,5c]pyridin-4-one derivatives with dual activity at angiotensin II type 1 receptor and peroxisome proliferator-activated receptor-gamma. Bioorg Med Chem Lett, 2013; 23 (3): 767-772.

Celik, L, Lund, JD, and Schiott, B. Conformational dynamics of the estrogen receptor alpha: molecular dynamics simulations of the influence of binding site structure on protein dynamics. Biochemistry, 2007; 46 (7): 1743-1758.

Chang, F, Jaber, LA, Berlie, HD, and O'Connell, MB. Evolution of peroxisome proliferator-activated receptor agonists. Ann Pharmacother, 2007; 41 (6): 973-983.

Deng, XQ, Wang, HY, Zhao, YL, Xiang, ML, Jiang, PD, Cao, ZX, Zheng, YZ, Luo, SD, Yu, LT, Wei, YQ, and Yang, SY Pharmacophore modelling and virtual screening for identification of new Aurora-A kinase inhibitors. Chem Biol Drug Des, 2008; 71 (6): 533-539.

Farce, A, Renault, N, and Chavatte, P. Structural insight into PPARgamma ligands binding. Curr Med Chem, 2009; 16 (14): 1768-1789. Feldman, PL, Lambert, MH, and Henke, BR. PPAR modulators and PPAR pan agonists for metabolic diseases: the next generation of 
drugs targeting peroxisome proliferator-activated receptors? Curr Top Med Chem, 2008; 8 (9): 728-749.

Fracchiolla, G, Laghezza, A, Piemontese, L, Tortorella, P, Mazza, F, Montanari, R, Pochetti, G, Lavecchia, A, Novellino, E, Pierno, S, Conte Camerino, D, and Loiodice, F. New 2-aryloxy-3-phenylpropanoic acids as peroxisome proliferator-activated receptors alpha/gamma dual agonists with improved potency and reduced adverse effects on skeletal muscle function. J Med Chem, 2009; 52 (20): 6382 6393.

Guner, OF. The impact of pharmacophore modeling in drug design. IDrugs, 2005; 8 (7): 567-572.

Henke, B. Peroxisome proliferator-activated receptor alpha/ gamma dual agonists for the treatment of type 2 diabetes. J Med Chem, 2004a; 47 (17): 4118 - 4127.

Henke, BR. 1. Peroxisome proliferator-activated receptor gamma (PPARgamma) ligands and their therapeutic utility. Prog Med Chem, 2004b; 42: 1-53.

Hiukka, A, Maranghi, M, Matikainen, N, and Taskinen, MR. PPARalpha: an emerging therapeutic target in diabetic microvascular damage. Nat Rev Endocrinol, 2010; 6 (8): 454-463.

Ikram, NKK, Durrant, JD, Muchtaridi, M, Zalaludin, AS, Purwitasari, N, Mohamed, N, Rahim, ASA, Lam, CK, Normi, YM, and Rahman, NA. A Virtual Screening Approach For Identifying Plants with Anti H5N1 Neuraminidase Activity. Journal of chemical information and modeling, 2015; 55 (2): 308-316.

Jones, D. Potential remains for PPAR-targeted drugs. Nat Rev Drug Discov, 2010; 9 (9): 668-669.

Kong, AP, Yamasaki, A, Ozaki, R, Saito, H, Asami, T, Ohwada, S, Ko, GT, Wong, CK, Leung, GT, Lee, KF, Yeung, CY, and Chan, JC. A randomized-controlled trial to investigate the effects of rivoglitazone, a novel PPAR gamma agonist on glucose-lipid control in type 2 diabetes. Diabetes Obes Metab, 2011; 13 (9): 806-813.

Koyama, H, Miller, DJ, Boueres, JK, Desai, RC, Jones, AB, Berger, JP, MacNaul, KL, Kelly, LJ, Doebber, TW, Wu, MS, Zhou, G, Wang, PR, Ippolito, MC, Chao, YS, Agrawal, AK, Franklin, R, Heck, JV, Wright, SD, Moller, DE, and Sahoo, SP. (2R)-2-ethylchromane-2carboxylic acids: discovery of novel PPARalpha/gamma dual agonists as antihyperglycemic and hypolipidemic agents. J Med Chem, 2004; 47 (12): 3255-3263.

Manetti, F, Forli, S, Maccari, L, Corelli, F, and Botta, M. 3D QSAR studies of the interaction between beta-tubulin and microtubule stabilizing antimitotic agents (MSAA). A combined pharmacophore generation and pseudoreceptor modeling approach applied to taxanes and epothilones. Farmaco, 2003; 58 (5): 357-361.

Martres, P, Faucher, N, Laroze, A, Pineau, O, Fouchet, MH, Potvain, F, Grillot, D, and Beneton, V. The discovery of equipotent PPARalpha/gamma dual activators. Bioorg Med Chem Lett, 2008; 18 (23): 6251-6254.

Muchtaridi, M, Yusuf, M, Diantini, A, Choi, SB, Al-Najjar, BO, Manurung, JV, Subarnas, A, Achmad, TH, Wardhani, SR, and Wahab, HA. Potential Activity of Fevicordin-A from Phaleria macrocarpa (Scheff) Boerl. Seeds as Estrogen Receptor Antagonist Based on Cytotoxicity and Molecular Modelling Studies. International journal of molecular sciences, 2014; 15 (5): 7225-7249.
Musfiroh, I, Muchtaridi, M, Muhtadi, A, Diantini, A, Hasanah, AN, Udin, LZ, Susilawati, Y, Mustarichie, R, Kartasasmita, RE, and Ibrahim, S. Cytotoxicity Studies of Xanthorrhizol and Its Mechanism Using Molecular Docking Simulation and Pharmacophore Modelling. 2013 .

Newman, DJ, and Cragg, GM. Natural Products as Sources of New Drugs over the Last 25 Years $\perp$. Journal of Natural Products, 2007; 70 (3): 461-477.

Oon Han, H, Kim, SH, Kim, KH, Hur, GC, Joo Yim, H, Chung, HK, Ho Woo, S, Dong Koo, K, Lee, CS, Sung Koh, J, and Kim, GT. Design and synthesis of oxime ethers of alpha-acyl-beta-phenylpropanoic acids as PPAR dual agonists. Bioorg Med Chem Lett, 2007; 17 (4): $937-$ 941.

Pearson, ER. Pharmacogenetics and future strategies in treating hyperglycaemia in diabetes. Front Biosci (Landmark Ed), 2009; 14: 4348 4362.

Pourcet, B, Fruchart, JC, Staels, B, and Glineur, C. Selective PPAR modulators, dual and pan PPAR agonists: multimodal drugs for the treatment of type 2 diabetes and atherosclerosis. Expert Opin Emerg Drugs, 2006; 11 (3): 379-401.

Schimke, K, and Davis, TM. Drug evaluation: rivoglitazone, a new oral therapy for the treatment of type 2 diabetes. Curr Opin Investig Drugs, 2007; 8 (4): 338-344.

Shibata, Y, Kagechika, K, Yamaguchi, M, Kubo, H, and Usui, $\mathrm{H}$. Design, synthesis and evaluation of novel zwitterionic compounds as PPARalpha/gamma dual agonists (1). Bioorg Med Chem Lett, 2012; 22 (23): 7075-7079.

Sutter, J, Guner, OF, Hoffman, RD, Li, H, and Waldman, M. Effect Variables Weights and Tolerances in Predictive Model Generation. In Pharmacophore Perception, Development, and Use in Drug Design, edited by O. F. Guner. La Jolla: IUL Biotechnology Series, 2000; 501-510.

Wang, HY, Cao, ZX, Li, LL, Jiang, PD, Zhao, YL, Luo, SD, Yang, L, Wei, YQ, and Yang, SY. Pharmacophore modeling and virtual screening for designing potential PLK1 inhibitors. Bioorg Med Chem Lett, 2008; 18 (18): 4972-4977.

Yumuk, VD. Targeting components of the stress system as potential therapies for the metabolic syndrome: the peroxisomeproliferator-activated receptors. Ann N Y Acad Sci, 2006; 1083: 306-318.

\section{How to cite this article:}

Muchtaridi M, Low K, Lestari K. The in Silico Study of Nutmeg Seeds (Myristica Fragrans Houtt) as Peroxisome Proliferator Activated Receptor Gamma Activator Using 3d-Qsar Pharmacophore Modelling. J App Pharm Sci, 2016; 6 (09): 048053 